\title{
DETERMINACIÓN DEL SEXO MEDIANTE LA TÉCNICA DE REACCIÓN EN CADENA DE LA POLIMERASA EN CAMÉLIDOS SUDAMERICANOS
}

\author{
Use of Polimerase Chain Reaction for Sexing South American Camelids \\ Vanya Montenegro V. ${ }^{1}$, Lenin Maturrano H. ${ }^{1,2,3}$, Jane C. Wheeler ${ }^{2}$, Raúl Rosadio A. ${ }^{1,2}$
}

\section{RESUMEN}

Se reporta el desarrollo y optimizaciones de técnicas moleculares (PCR simple, múltiple y semi-anidada) para determinar el sexo de camélidos sudamericanos (CSA) amplificando la secuencia del gen Zinc Finger Protein (ZF). La técnica utilizó ADN obtenido de 28 muestras de sangre de alpacas, llamas y vicuñas, 20 muestras de heces de vicuñas y guanacos conservadas en etanol al 96\%, y 22 embriones de alpaca colectados entre 72 y 96 horas postmonta y preservados en etanol. Las muestras de ADN de sangre y heces fueron extraídas usando kits comerciales, y las de embriones aplicando tres métodos (ebullición, proteinasa K y fenol-cloroformo). Una vez optimizada la PCR simple para la detección de los genes ZFY y ZFX, se implementó la PCR múltiple para ADN de sangre y heces y la PCR semi-anidada para ADN de embriones. La técnica de PCR múltiple determinó el sexo correctamente en el 100\% de las muestras de ADN sanguíneo, en el 87.5\% de muestras de ADN de heces colectadas en 2008 y en el 50\% de las muestras de ADN de heces colectadas en 2004 y preservadas durante cuatro años antes del análisis. La prueba de PCR semi-anidada, sin embargo, no pudo ser optimizada.

Palabras clave: ADN, PCR, sexaje molecular, camélidos sudamericanos

\section{Abstract}

The objective of this study was to develop a PCR technique to determine the sex of South American camelids (CSA) using Zinc Finger Protein (ZF) sequences from blood and fecal samples, as well as cells from alpaca embryos. A total of 28 alpaca, llama and vicuña blood samples, 20 vicuña and guanaco fecal samples, and 22 alpaca embryos collected between 72 and 96 hours postcopula were used. The fecal and embryo samples were preserved in $96 \%$ and $70 \%$ ethanol respectively. DNA was extracted from blood and feces using commercial kits. Three methods (boiling, proteinase K and phenol-cloroform) were used to extract DNA from alpaca embryos. Two PCR techniques were developed to

\footnotetext{
${ }^{1}$ Sección de Biología y Genética Molecular, Facultad de Medicina Veterinaria, Universidad Nacional Mayor de San Marcos, Lima

${ }^{2}$ CONOPA - Instituto de Investigación y Desarrollo de Camélidos Sudamericanos, Lima

${ }^{3}$ E-mail: lenin.maturrano@gmail.com
} 
analyze DNA: multiplex (for fecal and blood sample DNA) and heminested PCR (for embryo cell DNA). The multiplex PCR accurately determined the sex in $100 \%$ of the DNA samples extracted from blood, in $87.5 \%$ of the samples extracted from fresh feces and in $50 \%$ of the 4 -year old fecal samples. The heminested PCR, however, could not be optimized.

Key words: DNA, PCR, sexing, South American camelids

\section{INTRODUCCIÓN}

Las técnicas de determinación del sexo son utilizadas en mamíferos, tanto con fines productivos para estimar el sexo de la futura cría en programas de transferencia de embriones, principalmente en bovinos (Thibier y Nimbart, 1995), como con fines de conservación o investigación en aquellas especies en las que no es posible observar el sexo del animal al que pertenece la muestra, como en el caso de animales silvestres como felinos (Pilgrim et al., 2005) o primates (Villensen y Fredsted, 2006). De las técnicas reportadas para determinar el sexo en mamíferos, la técnica de PCR es la más sensible, sencilla y rápida. La técnica se basa en la amplificación de segmentos de un gen presente sólo en el cromosoma Y, como el gen SRY (Pilgrim et al., 2005), o en la amplificación de segmentos de ADN presentes en ambos cromosomas sexuales pero con mutaciones diferenciales, como en el caso del gen Zinc Finger Protein (ZF) (Aasen y Medrano, 1990; Prithiviraj y Melnic, 2001).

El sexaje molecular, en muestras no invasivas, se emplea en varias especies de animales de vida silvestre (Vidya et al., 2003; Pilgrim et al., 2005; Villessen y Fredsted, 2006), y en muestras de sangre y tejidos con la finalidad de aplicarlas en el sexaje de embriones de especies domésticas (Pomp et al., 1995; Phua et al., 2003; Lemos et al., 2005). Similares técnicas han sido utilizadas en ADN sanguíneo de llamas y alpacas amplificando el gen SRY (Pomp et al., 1995; Arias y Huanca, 2009); sin embargo, no existen reportes de su utilización en muestras de ADN fecales ni embrionarias.
En el Perú se han iniciado estudios de diversidad genética en poblaciones de vicuñas y guanacos utilizando muestras de heces. La caracterización de estas poblaciones silvestres requiere en muchos casos informaciones sobre proporciones de machos y hembras, por lo que es necesario disponer de una prueba de sexaje molecular optimizada. En el presente estudio se reportan optimizaciones de técnicas de PCR para el sexaje molecular, inicialmente en muestras sanguíneas y, posteriormente, en $\mathrm{ADN}$ de heces y embriones, amplificando segmentos del gen Zinc Finger protein (ZF) utilizando tres cebadores específicos para camélidos sudamericanos diseñados por investigadores del Instituto de Investigación y Desarrollo de Camélidos Sudamericanos - CONOPA (Montenegro et al., 2007).

\section{Materiales y MÉtodos}

\section{Obtención de Muestras de ADN}

\section{Extracción de $A D N$ de sangre}

Se utilizaron 28 muestras de sangre extraídas mediante punción de la vena yugular, utilizando tubos al vacío con K3 EDTA al $15 \%$, obtenidas de 20 alpacas adultas de la Estación Experimental del Centro de Investigación IVITA (Maranganí, Cusco) y de ocho vicuñas (Cuadro 1) recolectadas con autorizaciones 016-2004-INRENA-IFFS-DCB, 021-2004-INRENA-IFFS-DCB，11 C/C2004-INRENA-IANP， 12 C/C-2004INRENA-IANP y 057-2008-INRENA-IFFSDCB. Para la extracción del ADN se utilizó la prueba "Promega Wizard DNA Purification 
Cuadro 1. Número y características de las muestras de ADN obtenidas de camélidos sudamericanos

\begin{tabular}{|c|c|c|c|c|}
\hline & \multirow[b]{2}{*}{ ADN sanguíneo } & \multicolumn{2}{|c|}{ ADN de heces } & \multirow{2}{*}{$\begin{array}{c}\text { ADN } \\
\text { embrionario }\end{array}$} \\
\hline & & $\begin{array}{l}\text { Heces colectadas } \\
\text { (2004) }\end{array}$ & $\begin{array}{c}\text { Heces colectadas } \\
\text { (2008) }\end{array}$ & \\
\hline Alpacas & $10\left(5 \mathrm{H}^{1}\right.$ y $\left.5 \mathrm{M}^{1}\right)$ & & $4(2 \mathrm{H} \mathrm{y} 2 \mathrm{M})^{\mathrm{c}}$ & 22 \\
\hline Llamas & $10(5 \mathrm{H}$ y $5 \mathrm{M})$ & & & \\
\hline Vicuñas & $8(4 \mathrm{Hy} 4 \mathrm{M})$ & $4(1 \mathrm{H} \text { y } 3 \mathrm{M})^{\mathrm{b}}$ & $2(1 \mathrm{H} \text { y } 1 \mathrm{M})^{\mathrm{c}}$ & \\
\hline Guanacos & & $8(2 \text { H y } 6 \mathrm{M})^{\mathrm{a}}$ & $2 \mathrm{M}^{\mathrm{c}}$ & \\
\hline Total: & $28(14$ H y $14 \mathrm{M})$ & $12(32$ H y $4 \mathrm{M})$ & $8(2$ H y $6 \mathrm{M})$ & 22 \\
\hline
\end{tabular}

kit" (Promega, Madison, USA), siguiendo las instrucciones del laboratorio comercial. Estas muestras de ADN fueron utilizadas como patrón en el proceso de optimización y desarrollo de las técnicas de PCR empleadas en el estudio.

\section{Extracción de ADN de heces}

Se trabajó con 20 muestras de heces de 12 vicuñas y 8 guanacos (Cuadro 1), obtenidas con las autorizaciones arriba indicadas. Las heces de vicuñas se obtuvieron directamente del recto del animal. Las heces de guanacos se colectaron de las letrinas inmediatamente después de observar defecar al animal y constatar el sexo con la ayuda de binoculares. Las muestras fueron transportadas y conservadas en etanol absoluto a temperatura ambiente y el ADN fue extraído usando la prueba comercial QIAamp Stool Mini Kit (QIAGEN).

\section{Extracción de $A D N$ de embriones}

Se utilizaron animales del Centro de Investigación IVITA, en Maranganí, Cusco. Se colectaron 22 embriones de alpaca (14 co- lectados 72 horas postmonta y 8 a las 96 horas postmonta) mediante la técnica quirúrgica descrita por Novoa et al. (1999). Los embriones fueron colocados en microtubos de polietileno conteniendo $200 \mu \mathrm{L}$ de etanol al $70 \%$ a $4{ }^{\circ} \mathrm{C}$ y transportados a la unidad de Biología y Genética Molecular de la Facultad de Medicina Veterinaria, Universidad Nacional Mayor de San Marcos, Lima. El etanol fue eliminado mediante pasajes del embrión en agua ultrapura y el ADN fue extraído tres semanas después de la colección empleando tres métodos aplicados al azar (ebullición, proteinasa $\mathrm{K}$ y fenol-cloroformo).

\section{Cuantificación de ADN}

La concentración y la tasa de pureza del ADN extraído de todas las muestras fueron determinadas mediante espectrofotometría a $260 \mathrm{~nm}$ y $280 \mathrm{~nm}$. La calidad del ADN fue verificada mediante electroforesis en un gel de agarosa.

\section{Optimización de las Técnicas de PCR}

Las muestras de ADN sanguíneo fueron utilizadas inicialmente para optimizar la 
Cuadro 2. Mezcla estándar y ciclos utilizados en el proceso de optimización de la PCR simple de ZFX-Y, PCR simple de ZFY, PCR múltiple y PCR semianidada para muestras de ADN de camélidos sudamericanos

\begin{tabular}{|c|c|c|c|c|}
\hline & ZFX-Y & ZFY & Múltiple & Semianidada \\
\hline $\mathrm{MgCl}_{2}(\mathrm{mM})^{\mathrm{a}}$ & 1.4 & 1.98 & 2.5 & \\
\hline $\operatorname{ADN}(p g)^{d}$ & 4,000 & 20,000 & 50,000 & $0.5(\mu \mathrm{L})^{\mathrm{e}}$ \\
\hline $\mathrm{BSA}(\mu \mathrm{g} / \mu \mathrm{L})$ & 1.2 & 0.8 & 1 & \\
\hline Formamida (\%) & -- & -- & 1 & \\
\hline $\begin{array}{l}\text { Cebador ZFX } 2 \\
(\text { pmol })^{\mathrm{c}}\end{array}$ & 12.5 & 12.5 & 25 & \\
\hline $\begin{array}{l}\text { Cebador ZFX } 4 \\
(\text { pmol })^{c}\end{array}$ & 12.5 & 12.5 & 25 & \\
\hline $\begin{array}{l}\text { Cebador ZFY } \\
(\text { pmol })^{\mathrm{c}}\end{array}$ & & & 25 & \\
\hline $\mathrm{dNTPs}(\mathrm{mM})^{\mathrm{b}}$ & 0.2 & 0.16 & 0.2 & \\
\hline Taq polimerasa $(\mathrm{U})^{\mathrm{a}}$ & 1 & 1 & 0.5 & \\
\hline Buffer de PCR $(X)^{\mathrm{a}}$ & 0.9 & 0.8 & 1 & \\
\hline Volumen final $(\mu \mathrm{L})$ & 21.7 & 25.2 & 20 & 12 \\
\hline Ciclos & $\begin{array}{c}95^{\circ} \mathrm{C} \times 5^{\prime} \\
35\left(95^{\circ} \mathrm{C} \times 30^{\prime \prime},\right. \\
56^{\circ} \mathrm{C} \times 45^{\prime \prime} \\
\left.72^{\circ} \mathrm{C} \times 45^{\prime \prime}\right) \\
72^{\circ} \mathrm{C} \times 5^{\prime}\end{array}$ & $\begin{array}{c}95^{\circ} \mathrm{C} \times 5^{\prime}, \\
35\left(95^{\circ} \mathrm{C} \times 30^{\prime \prime}\right. \\
52^{\circ} \mathrm{C} \times 45^{\prime \prime} \\
\left.72^{\circ} \mathrm{C} 45^{\prime \prime}\right) \\
72^{\circ} \mathrm{C} \times 5^{\prime}\end{array}$ & $\begin{array}{c}95^{\circ} \mathrm{C} \times 5^{\prime}, \\
35\left(95^{\circ} \mathrm{C} \times 30^{\prime \prime},\right. \\
52^{\circ} \mathrm{C} \times 45^{\prime \prime}, \\
\left.72^{\circ} \mathrm{C} 45^{\prime \prime}\right), \\
72^{\circ} \mathrm{C} \times 5^{\prime}\end{array}$ & \\
\hline
\end{tabular}

a Promega, Madison, USA; ${ }^{\mathrm{b}}$ Gibco; ${ }^{\mathrm{c}}$ Sigma Genosis; ${ }^{\mathrm{d}}$ Cantidades totales en la mezcla, ${ }^{\mathrm{e}}$ Cantidad de producto de la primera PCR

técnica de PCR simples para los genes ZFX y ZFY en formas individuales, para luego desarrollar y estandarizar un PCR múltiple y semianidado. Después de la estandarización para la amplificación de ambos genes en muestras sanguíneas, se procedió a extrapolar la técnica a muestras de ADN fecales y embrionarios.

El proceso de optimización en ADN de sangre, consistió en amplificar segmentos de diferentes tamaños del gen ZF altamente conservado en mamíferos, utilizando tres cebadores (Aasen y Medrano, 1990). Los protocolos utilizaron los cebadores ZFX2 y ZFX4 para amplificar un segmento de 250 pares de bases $(\mathrm{pb})$ presente en ambos cromosomas sexuales (ZFX y ZFY), y un tercero ZFY2 de reversa utilizado conjuntamente con el cebador ZFX2 para amplificar un segmento de $130 \mathrm{pb}$, presente solamente en el cromosoma Y (ZFY) (Montenegro et al., 2007).

Durante el proceso de optimización se trabajó con una mezcla de reactivos estándar (Cuadro 2) y se evaluaron ocho parámetros en forma individual. De esta forma, solo va- 
Cuadro 3. Condiciones evaluadas en el proceso de optimización de la PCR simple de ZFXY, PCR simple de ZFY, PCR múltiple y PCR semianidada

\begin{tabular}{|c|c|c|c|c|}
\hline & $\begin{array}{l}\text { Simple de } \\
\text { ZFX-Y }\end{array}$ & $\begin{array}{l}\text { Simple de } \\
\text { ZFY }\end{array}$ & Múltiple & Semianid ada ${ }^{a}$ \\
\hline $\begin{array}{l}\text { Temperatura de } \\
\text { alineación }\left({ }^{\circ} \mathrm{C}\right)\end{array}$ & $\begin{array}{c}58,60,62 y \\
64\end{array}$ & $\begin{array}{c}48,50,52 \mathrm{y} \\
54\end{array}$ & $49,51,53$ у 55 & $\begin{array}{c}52,54,56,58 y \\
60\end{array}$ \\
\hline $\begin{array}{l}\text { Concentración } \\
\text { de cloruro de } \\
\text { magnesio }(\mathrm{mM})\end{array}$ & $\begin{array}{c}1,1.4,1.8,2.3 \\
\text { y } 2.7\end{array}$ & $\begin{array}{l}1.2,1.6,2.0 \\
2.4,2.8 \text { y } 3.2\end{array}$ & $\begin{array}{c}2.0,2.5,3.0 \mathrm{y} \\
3.5\end{array}$ & \\
\hline $\begin{array}{l}\text { Cantidad de } \\
\text { ADN molde } \\
\text { (pg) }\end{array}$ & $\begin{array}{c}20,50,200 \\
400 \text { y } 200\end{array}$ & $\begin{array}{c}20,000 \mathrm{y} \\
40,000\end{array}$ & $\begin{array}{c}20,000,50,000 \\
\text { y } 100,000\end{array}$ & $\begin{array}{c}0.12,0.25,0.5 \\
1 \text { y } 2 \mu \mathrm{L}^{\mathrm{b}}\end{array}$ \\
\hline $\begin{array}{l}\text { Cebador ZFX } 2 \\
(\mathrm{pmol})\end{array}$ & -- & -- & $12.5,25$ у 50 & \\
\hline $\begin{array}{l}\text { Cebador ZFX } 4 \\
\text { (pmol) }\end{array}$ & -- & - & 25,75 y 50 & \\
\hline $\begin{array}{l}\text { Cebador ZFY } 2 \\
\text { (pmol) }\end{array}$ & -- & -- & 25 y 50 & \\
\hline $\mathrm{BSA}(\mu \mathrm{g} / \mu \mathrm{L})$ & $0.5,0.8$, y 1.2 & $0.5,0.8$, y 1.2 & $0.5,1,1.5$ у 2 & \\
\hline Formamida (\%) & & & $1,2,3$ y 4 & $1,2,3$ y 4 \\
\hline
\end{tabular}

${ }^{a}$ El primer PCR se llevó a cabo con las mismas condiciones que para ZFX

${ }^{\mathrm{b}}$ Cantidad del producto de la primera PCR

rió el parámetro a evaluar en el orden que se presentan en el Cuadro 3, quedando constantes los demás parámetros. Todas las reacciones incluyeron un control negativo (agua ultrapura en vez de ADN) y se utilizó un termociclador Applied Biosystems 2720. Una vez optimizada la PCR simple con muestras de sangre, se hizo lo mismo para desarrollar el PCR múltiple y posteriormente la anidada. Una vez optimizada la técnica de PCR múltiple se evaluaron todas las muestras de sangre y heces.

\section{Resolución de los Fragmentos Amplifi- cados}

Los productos de cada PCR fueron analizados en un gel de agarosa al $2 \%$ en solución tampón TBE 0.5X (Tris, Acido Bórico, EDTA), en una cámara de electroforesis horizontal junto a un marcador de peso molecular, para determinar el tamaño aproximado de los fragmentos amplificados. Los productos de PCR fueron teñidos con bromuro de etidio, visualizados en un transiluminador y fotografiados con una cámara Polaroid (DS 34). 
Cuadro 4. Cantidad y características de las muestras de ADN extraídas

\begin{tabular}{lcccc}
\hline & Muestras & $\begin{array}{c}\text { Concentración de } \\
\text { ADN }(\mathrm{ng} / \mu \mathrm{L})\end{array}$ & Pureza & Características \\
\hline ADN sanguíneo & 28 & $123.95(39-211)$ & $>1.8$ & $\begin{array}{c}\text { Mínima presencia de } \\
\text { ADN degradado } \\
\text { Moderada a máxima } \\
\text { presencia de ADN } \\
\text { degradado }\end{array}$ \\
ADN de heces & 20 & $100.06(1-265)$ & $0.2-1.7$ & --- \\
\hline ADN de embriones ${ }^{1}$ & 22 & --- & & \\
\hline${ }^{1}$ No se obtuvo ADN & & & &
\end{tabular}

Cuadro 5. Condiciones óptimas para la PCR simple de ZFX-Y, PCR simple de ZFY, y PCR múltiple

\begin{tabular}{|c|c|c|c|}
\hline & ZFX-Y & ZFY & Múltiple \\
\hline $\mathrm{MgCl}_{2}(\mathrm{mM})$ & 2.7 & 1.6 & 2.5 \\
\hline ADN (ng) & $>0.1$ & 25 & 20 \\
\hline $\mathrm{BSA}(\mu \mathrm{g} / \mu \mathrm{L})$ & 0.8 & 1.2 & 1 \\
\hline Formamida (\%) & --- & --- & 1 \\
\hline $\begin{array}{l}\text { Cebador ZFX } 2 \\
\text { (pmol) }\end{array}$ & 12.5 & 12.5 & 50 \\
\hline $\begin{array}{l}\text { Cebador ZFX } 4 \\
\text { (pmol) }\end{array}$ & 12.5 & 12.5 & 12.5 \\
\hline $\begin{array}{l}\text { Cebador ZFY } 2 \\
\text { (pmol) }\end{array}$ & --- & --- & 25 \\
\hline dNTPs (mM) & 0.2 & 0.16 & 0.2 \\
\hline Taq polimerasa $(\mathrm{U})$ & 1 & 1 & 0.5 \\
\hline Buffer de PCR (X) & 0.9 & 0.8 & 1 \\
\hline Volumen final $(\mu \mathrm{L})$ & 21.7 & 25.2 & 20 \\
\hline Ciclos & $\begin{array}{c}95^{\circ} \mathrm{C} \times 5^{\prime} ; \\
35\left(95^{\circ} \mathrm{C} \times 30^{\prime \prime},\right. \\
64^{\circ} \mathrm{C} \times 45^{\prime \prime}, \\
\left.72^{\circ} \mathrm{C} 45^{\prime \prime}\right), \\
72^{\circ} \mathrm{C} \times 5^{\prime}\end{array}$ & $\begin{array}{c}95^{\circ} \mathrm{C} \times 5^{\prime} ; \\
35\left(95^{\circ} \mathrm{C} \times 30^{\prime \prime},\right. \\
52^{\circ} \mathrm{C} \times 45^{\prime \prime}, \\
\left.72^{\circ} \mathrm{C} 45^{\prime \prime}\right), \\
72^{\circ} \mathrm{C} \times 5^{\prime}\end{array}$ & $\begin{array}{c}95^{\circ} \mathrm{C} \times 5^{\prime} \\
35\left(95^{\circ} \mathrm{C} \times 30^{\prime \prime},\right. \\
53^{\circ} \mathrm{C} \times 45^{\prime \prime} \\
\left.72^{\circ} \mathrm{C} 45^{\prime \prime}\right) \\
72^{\circ} \mathrm{C} \times 5^{\prime}\end{array}$ \\
\hline
\end{tabular}


Cuadro 6. Resultados de la determinación del sexo de camélidos sudamericanos mediante PCR múltiple utilizando ADN de heces

\begin{tabular}{cccc}
\hline $\begin{array}{c}\text { Coincidencia de sexo } \\
\text { mediante PCR con sexo } \\
\text { fenotípico }\end{array}$ & $\begin{array}{c}\text { Muestras colectadas } \\
\text { hace 4 años }\end{array}$ & Muestras frescas & Total \\
\hline Positivo & $6(50 \%)$ & $7(87.5 \%)$ & $13(65 \%)$ \\
Negativo & $6(50 \%)$ & $1(12.5 \%)$ & $7(35 \%)$ \\
\hline Total & $12(100 \%)$ & $8(100 \%)$ & $20(100 \%)$ \\
\hline
\end{tabular}

\section{Interpretación de Resultados}

Los animales cuyas muestras presentaron solamente la amplificación de un producto de PCR de $250 \mathrm{pb}(\mathrm{ZFX}-\mathrm{Y})$ fueron diagnosticados como hembras y aquellos que mostraron dos amplicones simultáneos, uno de $250 \mathrm{pb}$ (ZFX-Y) y otro de $130 \mathrm{pb}$ (ZFY), fueron diagnosticados como machos.

\section{Resultados y Discusión}

El ADN extraído de sangre de alpacas y llamas tenía una alta concentración (45-201 $\mathrm{ng} / \mu \mathrm{L}$ ) y buena tasa de pureza (>1.8 y mínima presencia de degradación), corroborando similares características reportadas para otras especies (Chu et al., 2006). El ADN sanguíneo de animales silvestres fue, igualmente, de alta concentración $(39-211 \mathrm{ng} / \mu \mathrm{L})$ y buena pureza (>1.8) (Cuadro 4).

La concentración y pureza de ADN de muestras fecales varió dependiendo del tiempo recolectado. Las cuatro muestras frescas de alpacas obtenidas en 2008 tuvieron concentraciones mayores (15-265 $\mathrm{ng} / \mu \mathrm{L})$ comparadas con las obtenidas en el 2004 y preservadas durante cuatro años en el laboratorio antes de la extracción (1-172 ng/ $\mu \mathrm{L})$. Todas las muestras sin distinción de fecha mostraron el ADN degradado (datos no mostrados). La calidad del ADN extraído de heces fue semejante a lo encontrado en ADN de heces obtenido en humanos (Deuter et al., 1995), elefantes (Vidya et al., 2003), felinos (Pilgrim et al., 2005) y primates no humanos (Villensen y Fredsted, 2006). La degradación posiblemente se deba a que el ADN, proveniente de las células exfoliadas de la mucosa del colon, se mezcle con la flora intestinal y se exponga al medio ambiente una vez expulsado. La baja tasa de pureza se debería, además, a la gran cantidad de residuos (polisacáridos complejos, lípidos y proteínas) presentes en la materia fecal, que es difícil eliminar durante la extracción (Wasser et al., 1997; Nsubuga et al., 2004). La baja cantidad y degradación de ADN observada pudo deberse a la escasa presencia de células epiteliales descamadas (Deuter et al., 1995; Chu et al., 2006), lo que motivó la necesidad de incrementar la cantidad de ADN molde en la PCR múltiple.

Se verificó la presencia de los embriones antes de la extracción pero no se logró detectar ADN, probablemente debido a la baja cantidad de células en los embriones utilizados o la capacidad de extracción de las técnicas utilizadas; sin embargo, no existen reportes al respecto. 
Las exitosas amplificaciones de los segmentos individuales ZFX y ZFY en PCR simples, así como la detección conjunta de ambos segmentos ZFX y ZFY en PCR múltiple se detallan en el Cuadro 5. La ampificación óptima del ZFY fue conseguida utilizando temperatura de alineación de $52^{\circ} \mathrm{C}$ y concentraciones de $\mathrm{Mg}$ de $1.6 \mathrm{mM}$ y seroalbúmina bovina (BSA) de $1.2 \mu \mathrm{g} / \mu \mathrm{L}$ que permitieron amplificar un buen producto en muestras conteniendo hasta $25 \mathrm{ng}$ de ADN. Para amplificar óptimamente el segmento ZFX-Y se necesitó $64{ }^{\circ} \mathrm{C}$ de temperatura con concentraciones de $\mathrm{Mg}$ de $2.7 \mathrm{mM}$ y BSA de $0.8 \mu \mathrm{g} / \mu \mathrm{L}$ necesarios en la obtención de productos visibles en muestras con más de 0.1 ng de ADN.

Las condiciones evaluadas para optimizar la PCR múltiple determinó que para amplificar ópticamente ambos segmentos se necesitaron utilizar las siguientes condiciones: $53{ }^{\circ} \mathrm{C}$ de temperatura de alineación, $2.5 \mathrm{mM}$ de $\mathrm{Cl}_{2} \mathrm{Mg}, 1 \%$ de $\mathrm{BSA}, 1 \%$ de formamida, 50 pmol del cebador ZFX2, 12.5 pmol de ZFX4 y 25 pmol de ZFY2 (Cuadro 5). Con estas condiciones se logró obtener buenos productos en concentraciones de ADN de hasta $20 \mathrm{ng}$.

Debe indicarse que a pesar de lograr amplificar el segmento de ZFY, en la técnica de PCR anidada, utilizando como molde el segmento amplificado de ZFX-Y, no se logró amplificar el segmento ZFY en forma consistente en una primera ronda, y algunas veces incluso con falsos resultados. Estas inconsistencias en los resultados pueden explicarse por la alineación inespecífica del cebador ZFY2 al cromosoma X, altamente concentrado en el ADN, después de una primera amplificación en la técnica de PCR anidada, o producto de contaminaciones altamente sensibles en la PCR anidada (GarcíaQuintanilla et al., 2000).

La optimización de la PCR múltiple permitió disminuir la cantidad de falsos negativos corroborando previas observaciones reportadas por Ortega et al. (2004). La amplificación de solamente un segmento en una
PCR simple puede sugerir erróneamente el sexaje como hembra, ya que la no amplificación del segmento propio del macho podría ser consecuencia de la degradación de la muestra (problema frecuente en ADN extraído de heces), y no necesariamente ser una muestra perteneciente a una hembra (Aasen y Medrano, 1990; Prithiviraj y Melnick, 2001; Pilgrim et al., 2005). La técnica de PCR múltiple desarrollada en el presente estudio permite la amplificación de segmentos específicos de cada cromosoma sexual, que al ser de pequeño tamaño facilita el uso en muestras degradadas como el ADN obtenido de heces (Villensen y Fredsted, 2006). Consecuentemente, la utilización de la PCR múltiple en el sexaje molecular tiene una potencial ventaja frente al método propuesto por Arias y Huanca (2009), quienes sustentan el sexaje en la detección de una sola banda diagnóstica. La aplicación de la técnica de PCR múltiple en ADN sanguíneo determinó que el sexaje molecular concordó con el sexo fenótipico en el 100\% de las muestras (Fig. 1, Cuadro 6), coincidiendo con lo encontrado por GarcíaMuro et al. (1996) en caninos y Lemos et al. (2005) en bovinos, debido a la alta calidad y cantidad del ADN obtenido en estas muestras.

Los porcentajes de la correcta identificación de sexo mediante la técnica de PCR múltiple en muestras de ADN fecal (Cuadro 6) fueron similares a los obtenidos por otros investigadores (Wasser et al., 1997; Pilgrim et al., 2005) quienes identificaron correctamente el sexo en el $50-100 \%$ de las muestras usando ADN de heces de osos y felinos, respectivamente. El amplio margen de sensibilidad de la prueba en muestras de heces tal vez sea producto de la baja concentración de ADN y presencia de inhibidores de PCR y ADN degradado, lo cual es frecuentemente observado en muestras de ADN fecales. Por otro lado, las fallas en la amplificación en algunas muestras fecales en el estudio (Fig. 2), podrían deberse a factores tales como método de colección y conservación (etanol al $70 \%$ ), protocolo de extracción (QIAGEN QIAamp ${ }^{\circledR}$ Stool Mini Kit), condiciones 


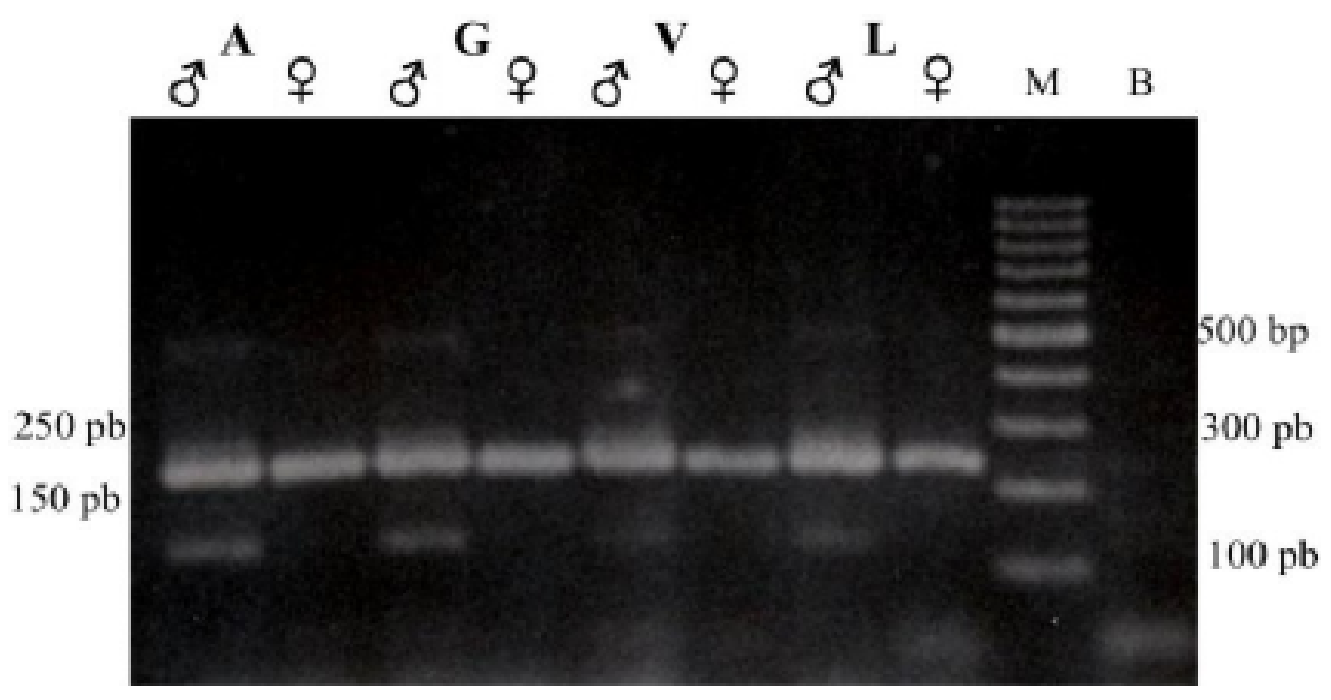

Figura 1. PCR múltiple utilizando muestras de ADN extraído de sangre de camélidos sudamericanos. $\mathrm{V}=$ vicuña; $\mathrm{G}=$ guanaco; $\mathrm{A}=$ alpaca; $\mathrm{L}=$ llama; $=$ hembra; $\hat{\delta}=$ macho; $\mathrm{M}=$ marcador de $100 \mathrm{pb} ; \mathrm{B}=$ blanco de PCR

\section{$\begin{array}{llllllllllllll}1 & 2 & 3 & 4 & 5 & 6 & 7 & 8 & 9 & 10 & 1112 & 13 & \mathrm{PM}\end{array}$

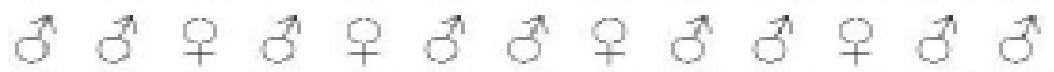 \\ V G G V V G G G V VA A G}

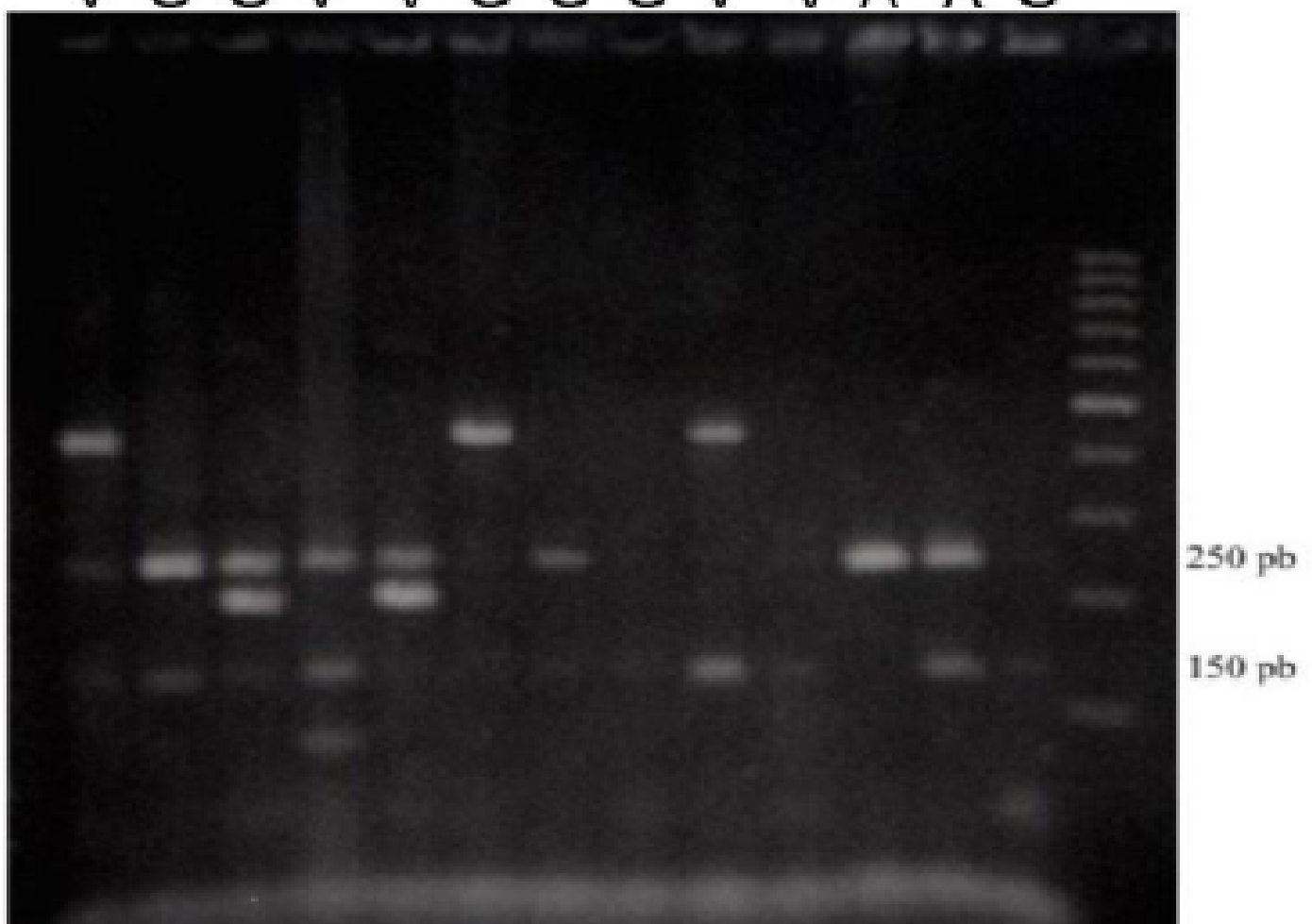

Figura 2. PCR múltiple utilizando muestras de ADN extraído de heces de camélidns sudamericanos silvestres. $\mathrm{V}=$ vicuña; $\mathrm{G}=$ guanaco; $\mathrm{A}=$ alpaca; $\mathrm{Q}=$ hembra; $\hat{\delta}=$ macho; $\mathrm{PM}=$ marcador de $100 \mathrm{pb}$ 
medioambientales en la época de colección, la dieta y la especie animal (Nsubuga et al., 2004; Chu et al., 2006). Sin embargo, en el presente estudio, la diferencia de éxito en muestras colectadas en 2004 y 2008 (Cuadro 6), evidencian la influencia del tiempo trascurrido desde la colección de las muestras a la fecha de extracción y/o del método de conservación, como factores negativos para la amplificación de segmentos de ADN determinantes de sexo (Wasser et al., 1997; Nsubuga et al., 2004).

La técnica de PCR múltiple determinó el sexo correctamente en el $100 \%$ de las muestras de ADN sanguíneo, en el $87.5 \%$ de muestras de ADN de heces colectadas en 2008 y en el $50 \%$ de las muestras de ADN de heces colectadas en 2004 y preservadas durante cuatro años antes del análisis.

\section{Conclusión}

Se desarrolló una técnica de PCR múltiple que permitió determinar el sexo de camélidos sudamericanos a partir de muestras de sangre. Esta prueba podría ser aplicada con un grado de éxito de $87.5 \%$ en muestras frescas de heces de camélidos sudamericanos silvestres.

\section{LiTERATURA Citada}

1. Aasen E, Medrano JF. 1990. Amplification of the ZFY and ZFX genes for sex indentification in humans, cattle, sheep and goats. Biotechnology 8: 12791281.

2. Arias N, Huanca W. 2009. Un método para el sexaje por ADN de alpaca amplificando el gen SRY mediante PCR. Rev Inv Vet, Perú 20: 203-207.

3. Chu J, Lin Y, Wu H. 2006. Applicability of non invasive, sampling in population genetic study of Taiwanwanese machaques (Macaca cyclopis). Taiwania 51: 258-265.
4. Deuter RS, Pietsch, Hertel S, Müller

O. 1995. A method for preparation of fecal DNA suitable PCR. Nucleic Acids Res 23: 3800-3801.

5. García-Muro E, Aznar MP, Rodellar C, Zaragoza P. 1996. Sex-specific PCR/RFLPs in the canine ZFY/ZFX loci. Anim Genet 28: 150-158.

6. García-Quintanilla A, García L, Tudó G, Navarra M, González J, Jiménez MT. 2000. Single-tube balanced heminested PCR for detecting Mycobacterium tuberculosis in smearnegative samples. J Clin Microbiol 38: 1166-1169.

7. Lemos DC, Lopes Ríos AF, Caetano LC, Lobo RB, Vila RA, Martelli L, Takeuchi PL, Ramos ES. 2005. Use of the TSPY gene for sexing cattle. Genet Mol Biol 28: 117-119.

8. Montenegro V, Maturrano L, Wheeler JC, Rosadio R. 2007. Desarrollo de una técnica rápida mediante PCR para determinación del sexo en camélidos sudamericanos domésticos. En: I Congreso Nacional de Reproducción y Mejoramiento Genético de Camélidos Sudamericanos. Huancavelica, Perú.

9. Novoa C, Franco E, García W, Pezo D. 1999. Dosis de gonadotropinas (eCG y hCG), superovulación y obtención de embriones en alpacas. Rev Inv Vet, Perú 10(1): 48-53.

10. Nsubuga AM, Robbins MM, Roeder AD, Morin PA, Boesch SC, Vigilant L. 2004. Factors affecting the amount of genomic DNA extracted from ape faeces and the identification of fan improved simple storage method. Mol Ecol 13: 2089-2094.

11. Ortega J, Franco M, Adams BA, Ralls K, Maldonado JE. 2004. A reliable noninvasive method for sex determination in the endangered San Joaquin kit fox (Vulpes macrotes mutica) and other canids. Conserv Genet 5: 715-718.

12. Phua A, Abdullah R, Mohamed Z. 2003. A PCR based sex determination method for possible application in caprine gender selection by simultaneous 
amplification of the Sry and Aml-X Genes. J Reprod Dev 49: 307-311.

13. Prithiviraj F, Melnick J. 2001. Molecular sexing eutherian mammals. Mol Ecol Notes 1: 350-353.

14. Pilgrim KL, Mckeelvey KS, Riddle AE, Schwartz MK. 2005. Felid sex identification based on noninvasive genetic samples. Mol Ecol Notes 5: 60-61.

15. Pomp D, Good BA, Geiser RD, Corbin CJ, Conley AJ. 1995. Sex identification in mammals with polymerase chain reaction and its use to examine sex effects on diameter of day 10 or 11 pig embryos. J Anim Sci 73: 1408-1415.

16. Thibier M, Nimbart M. 1995. The sexing of bovine embryos in the field. Theriogenology 43: 71-80.
17. Vidya TNC, Roshan V, Aravazhagan C, Sukumar R. 2003. Application of molecular sexing to free-ranging Asian elephant (Elephas maximus) populations in southern India. Curr Sci India 85: 10741077.

18. Villesen P, Fredsted T. 2006. Fast and non-invasive PCR sexing of primates: apes, old world monkeys, new world monkeys and Strepsirrhines. BMC Ecology 6: 8. [Internet]. Available in: http://www.biomedcentral.com/14726785/6/8

19. Wasser SK, Houston CS, Koehler GM, Cadd GG, Fain R. 1997. Techniques for application of faecal DNA field studies of Ursids. Mol Ecol 6: 1091-1097. 